\title{
Effects of Halide Ions on Current Oscillation during Electrocrystallization of Cadmium
}

\author{
Naoyuki SHINOHARA*, Norio KANEKO and Hiroyuki NEZU \\ Received September 16, 1994 ; Accepted October, 1994
}

\begin{abstract}
The effects of halide ions $\left(\mathrm{C1}^{-}, \mathrm{Br}^{-}\right.$and $\left.\mathrm{I}^{-}\right)$on the inhibitory behavior of $\mathrm{N}, \mathrm{N}-$ bis(decaoxyethylene) octadecylamine (DOOA) for the reduction of cadmium ion $\left(\mathrm{Cd}^{2+}\right)$, on the current oscillation during potentiostatic electrocrystallization of cadmium in the presence of DOOA and on the surface morphology of electrodeposited cadmium have been studied by electrochemical methods and electron microscopic observation. The reduction of $\mathrm{Cd}^{2}+$ was inhibited by adsorption effect of DOOA in the range of potentials from -0.8 to $-1.4 \mathrm{~V}$. The inhibitory behavior of DOOA for the reduction of $\mathrm{Cd}^{2}+$ was weakened by addition of halide ions in the order that their specific adsorption became stronger $\left(\mathrm{Cl}^{-}<\right.$ $\mathrm{Br}^{-}<\mathrm{I}^{-}$). Amplitude of the current oscillations became smaller and period became shorter with increase in concentrations of halide ions, and the current oscillation disappeared at high concentrations of halide ions. These effects of halide ions became marked in the order $\mathrm{Cl}^{-}, \mathrm{Br}^{-}$and $\mathrm{I}^{-}$. Surface roughness of electrodeposited cadmium obtained in the presence of DOOA and halide ions became larger and morphology of electrodeposited cadmium crystals became regular with increase in concentrations of halide ions. These effects of halide ions on electrocrystallization of cadmium may result from specific adsorption of $\mathrm{Cd}^{2}+$ induced by halide ions.
\end{abstract}

\section{INTRODUCTION}

The adsorption of N,N - bis(polyoxyethylene)octadecylamines (POOA) and its inhibitory behavior for the reduction of metal ions had been studied by polarographic methods in our previous papers ${ }^{1 \sim 3)}$. POOA exhibited the electrocapilary characteristics similar to that of tetraalkylammonium ions ${ }^{4 \sim 6)}$ and inhibited the reduction of cadmium ion $\left(\mathrm{Cd}^{2+}\right)$ strongly 3$)$. The halide ions such as $\mathrm{Cl}^{-}, \mathrm{Br}^{-}$and $\mathrm{I}^{-}$were specifically adsorbed on dropping mercury electrode and induced specific adsorption of $\mathrm{Cd}^{2+7 \sim 9)}$. The inhibitory behavior of POOA was weakened by halide ions in the order that the specific adsorption of halide ions became strong10).

On the other hand, the current oscillations were observed during the potentiostatic electro-

Factly of Engineering, Shinshu University (500 Wakasato, Nagano, 380, Japan)

Key Words: Current Oscillation, N,N-Bis(decaoxyethylene)octadecylamine, Halide Ion crystallization of cadmium from acidic cadmium sulfate solutions containing POOA on a cadmium cathode depending on the experimental conditions (potential, concentrations of POOA and $\left.\mathrm{Cd}^{2}+\right)^{11,12)}$. These current oscillations resulted from the increase and decrease in surface concentration of $\mathrm{Cd}^{2}+$ which attended the disappearance and appearance of strong inhibitory behavior of POOA for the reduction of $\mathrm{Cd}^{2+}$. Consequently, if the inhibitory behavior of POOA were also weakened on a cadmium cathode by halide ions in a similar manner as on a dropping mercury electrode, the amplitudes and periods of the current oscillation would be changed and the morphology of electrodeposited cadmium would be transformed. The purpose of this investigation was to study the effect of halide ions on the amplitudes and periods of the current oscillation during electrocrystallization of cadmium in the presence of $\mathrm{N}, \mathrm{N}$ - bis(decaoxyethylene)octadecylamine (DOOA) and on the surface morphology 
of electrodeposited cadmium which was obtained in the presence of DOOA.

\section{EXPERIMENTAL}

\subsection{Apparatus and procedure}

A Hokuto Denko Model HA-310 potentiostat/galvanostat was used in potentiostatic electrocrystallization of cadmium. Experiments were carried out using a three electrodes system and the cathode potential during electrocrystallization of cadmium was maintained at constant referred to a saturated calomel electrode (sce). Current-potential curves under potentiostatic conditions were obtained by plotting steady state current against applied potentials12). Current-time curves during the potentiostatic electrocrystallization were registered using a Toa Electronics Model INR - 6012 recorder. A cell having a volume of $100 \mathrm{~cm}^{3}$ was used. Temperature was maintained at $25 \pm 1^{\circ} \mathrm{C}$. The surface morphology of electrodeposited cadmium was observed using a Nihon Denshi Model JSM 5300 scanning electron microscope.

\subsection{Chemicals and electrode materials}

Sulfuric acid $\left(\mathrm{H}_{2} \mathrm{SO}_{4}\right)$ and potassium halide $(\mathrm{KCl}, \mathrm{KBr}, \mathrm{KI})$ were guaranteed reagents of Wako Pure Chemical Industries, Ltd.. Cadmium sulfate $\left(\mathrm{CdSO}_{4}\right)$ was a guaranteed reagent of Nakarai Tesque Inc. and $\mathrm{N}, \mathrm{N}-$ bis (decaoxyethylene)octadecylamine $\left\{\right.$ DOOA, $\mathrm{C}_{18} \mathrm{H}_{37} \mathrm{~N}$ $\left.\left.\left[\mathrm{CH}_{2} \mathrm{CH}_{2} \mathrm{O}\right)_{10} \mathrm{H}\right]_{2}\right\}$ was a. guaranteed reagent of Kao Co.. All the reagents were used without further purification and the solutions were prepared in redistilled water. A cadmium cathode was prepared by electrodeposition of cadmium from an acidic cadmium sulfate solution $(0.5 \mathrm{M}$ $\mathrm{H}_{2} \mathrm{SO}_{4}+0.4 \mathrm{M} \mathrm{CdSO}{ }_{4}+0.125 \mathrm{mM} \mathrm{DOOA}, \mathrm{M}=$ $\mathrm{mol} \cdot \mathrm{dm}-3$ ) on a low carbon steel plate of $7 \mathrm{~cm}^{2}$ surface area (Nisshin Steel Co.). The cadmium cathode was obtained using pulsed electrolysis, a current pulse (at $5 \mathrm{~A} \mathrm{dm}^{-2}$ for $3 \mathrm{~s}$ and $1.5 \mathrm{~A} \mathrm{dm}^{-2}$ for 6s) was applied two time at the beginning of electrolysis in order to accelerate the nucleation of cadmium crystal, then the current density was kept constant at $1.5 \mathrm{~A} \mathrm{dm-2}$ for $1330 \mathrm{~s}$. Pure platinum plate of approximate $10 \mathrm{~cm}^{2}$ surface area (Tanaka Kikinzoku Kogyo, Inc.; 99.9\%) was used as the anode.

\section{RESULTS AND DISCUSSION}

\subsection{Effects of halide ions on the inhibitory} behavior of DOOA

Figure 1 shows current-potential curves measured in acidic cadmium sulfate solutions containing DOOA and/or halide ions $\left(\mathrm{Cl}^{-}, \mathrm{Br}^{-}\right.$, $\left.\mathrm{I}^{-}\right)$using an electrodeposited cadmium as a cathode under potentiostatic conditions. The reduction current of $\mathrm{Cd}^{2+}$ was steeply increased at the potentials more negative than $-0.62 \mathrm{~V}$ in the absence of these substances (Fig. 1 curve 1). Addition of halide ions alone did not show any effect on $\mathrm{Cd}^{2+}$ reduction (Fig. 1 curve 2), but in the presence of DOOA a $\mathrm{N}$-shaped currentpotential curve was obtained (Fig. 1 curve 3 ). The dependance of inhibitory behavior of DOOA for the reduction of $\mathrm{Cd}^{2+}$ upon the cathode potential was reported in previous paper ${ }^{12}$ ). By adding halide ions the reduction current was increased in the order $\mathrm{Cl}^{-}, \mathrm{Br}^{-}$and $\mathrm{I}^{-}$(Fig.1 curves 4-6). This order agreed with that the specific adsorption of halide ions became strong.

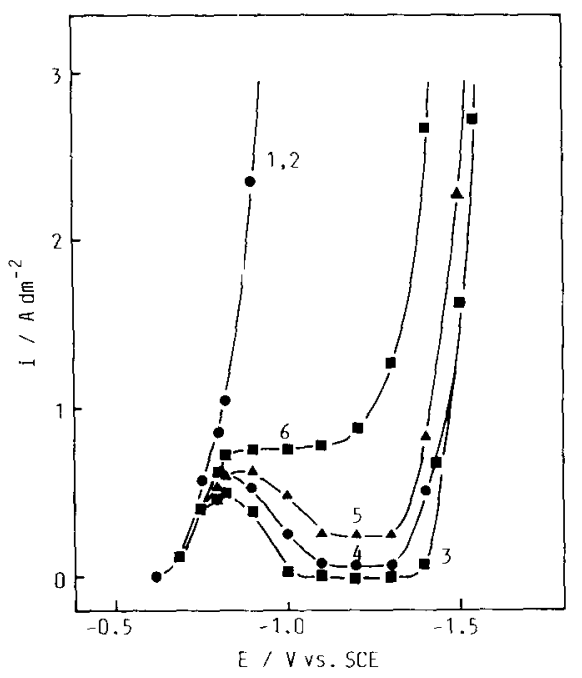

Fig. 1 Effects of DOOA and halide ions on the current-potential curves of cadmium ion under potentiostatic conditions.

1) $0.5 \mathrm{M} \mathrm{H}_{2} \mathrm{SO}_{4}+0.1 \mathrm{M} \mathrm{CdSO}_{4}$, 2) 1) $+5 \mathrm{mM} \mathrm{KCl}$, $\mathrm{KBr}$ or $\mathrm{KI}$, 3) 1 ) $+5 \mathrm{mM}$ DOOA, 4) 3) $+5 \mathrm{mM} \mathrm{KCl}$, 5) 3) +5mM KBr, 6) 3) +5mM KI. 
It has already turned our in our polarographic study ${ }^{10)}$ that adsorption of DOOA is not affected by halide ions in the range of potentials from -0.5 to $-1.5 \mathrm{~V}$, but the inhibitory behavior of DOOA for the reduction of $\mathrm{Cd}^{2}+$ is weakened in such a potential range by addition of halide ions. It has been established by some basic studies about specific adsorption of $\mathrm{Cd}^{2}+$ on a mercury cathode ${ }^{7 \sim 9}$ ) that $\mathrm{Cd}^{2}+$ is not adsorbed on a mercury cathode, but it is specifically adsorbed on a mercury cathode in the presence of specifically adsorbable anions such as $\mathrm{Cl}^{-}, \mathrm{Br}^{-}$and $\mathrm{I}^{-}$. From that the restoring effects of halide ions on the reduction of $\mathrm{Cd}^{2}+$ inhibited by DOOA is increased in the order that specific adsorption of halide ions become strong $\left(\mathrm{Cl}^{-}<\mathrm{Br}^{-}<\mathrm{I}^{-}\right.$, Fig. 1 curves $^{3 \sim 6)}$, it is indicated that the increase in reduction current of $\mathrm{Cd}^{2}+$ should relate to specific adsorption of halide ions. The specific adsorption of $\mathrm{Cd}^{2}+$ may also be induced on a cadmium cathode by halide ions as sim:lar as on a mercury cathode.

\subsection{Effects of halide ions on current oscilla- tion}

Figure 2 shows effect of $\mathrm{Br}^{-}$on the current oscillations and Fig. 3 shows an enlarged schematic diagram of the oscillations. The current oscillation with amplitudes of ca. $8 \mathrm{~A} \mathrm{dm}^{-2}$ and periods of ca. 12s was observed during electrocrystallization of cadmium in the presence of $5 \mathrm{mM}$ DOOA (Fig. 2 curve 1). The current showed maximum value of ca. $8 \mathrm{~A} \mathrm{dm-2} \mathrm{(Fig.} 3$ a) and decreased to ca. $3.5 \mathrm{~A} \mathrm{dm}^{-2}$ (Fig. $3 \mathrm{~b}$ ) vibrating with small amplitudes and short periods. Then, the current abruptly decreased to ca. $0.3 \mathrm{~A} \mathrm{dm}^{-2}$ (Fig. $3 \mathrm{c}$ ) and maintained lower value (Fig. $3 \mathrm{c}-$ d). The activated time (Fig. $3 \mathrm{~A}$ ) and inhibited time (Fig. $3 \mathrm{I}$ ) were repeated with time and the current oscillated with large amplitudes and long period. The amplitudes of the oscillation became smaller (5.8 A dm-2) and the periods became shorter $(3.1 \mathrm{~s})$ when $0.5 \mathrm{mM} \mathrm{Br}^{-}$was added into the solution (Fig. 2 curve 2). The current oscillation disappeared and the current showed a constant value of $3.7 \mathrm{Adm}^{-2}$ when $5 \mathrm{mM} \mathrm{Br}^{-}$was added (Fig. 2 curve 3 ). The similar results were also obtained with $\mathrm{Cl}^{-}$and $\mathrm{I}^{-}$.

Figure 4 shows the influences of $\mathrm{Cl}^{-}, \mathrm{Br}^{-}$and $\mathrm{I}^{-}$upon the $\mathrm{Cd}^{2+}$ reduction in the presence of DOOA. The current oscillation with amplitudes of ca. $7.8 \mathrm{Adm}^{-2}$ and periods of ca. $5.8 \mathrm{~s}$ was observed in the presence of $1 \mathrm{mM} \mathrm{Cl}^{-}$(Fig. 4 curve 1). When $1 \mathrm{mM} \mathrm{Br}{ }^{-}$was added, the current oscillated with smaller anplitude (ca. $5 \mathrm{~A} \mathrm{dm}^{-2}$ ) and shorter periods (ca. $2.3 \mathrm{~s}$ ) compared with those
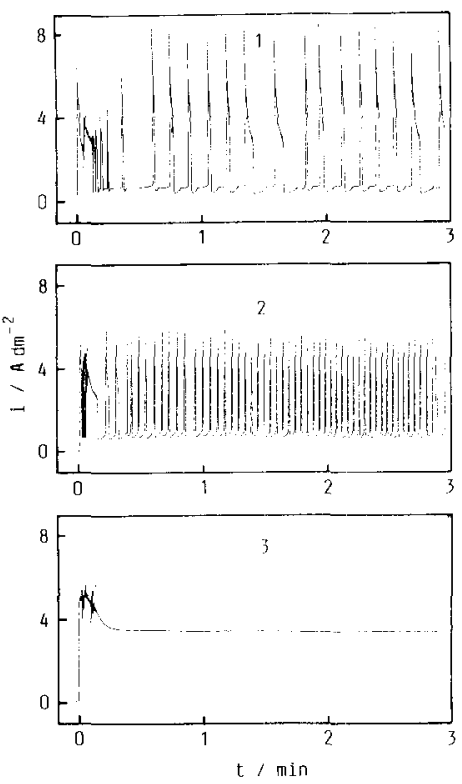

Fig. 2 Effect of $\mathrm{Br}^{-}$on the current oscillation during electrocrystallization of cadmium in the presence of DOOA at $-0.95 \mathrm{~V}$.

1) $0.5 \mathrm{M} \mathrm{H}_{2} \mathrm{SO}_{4}+0.4 \mathrm{M} \mathrm{ClSO}_{4}+5 \mathrm{mM} \mathrm{DOOA}$, 2) 1) $+0.5 \mathrm{mM} \mathrm{KBr}, 3) 1)+5 \mathrm{mM} \mathrm{KBr}$.

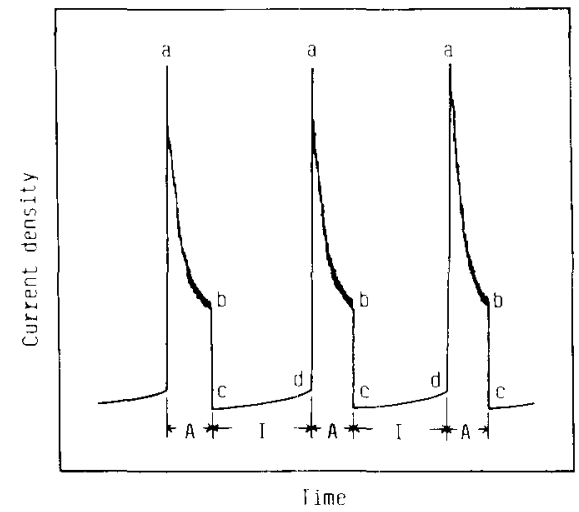

Fig. 3 Schematic diagram of current oscillation. 
in the presence of $\mathrm{Cl}^{-}$(Fig. 4 curve 2). The current showed a constant value of $3.7 \mathrm{Adm}^{-2}$ in the presence of $1 \mathrm{mM} \mathrm{I}^{-}$(Fig. 4 curve 3 ). It was turned out from the above results that the effects of the halide ions on the amplitudes and periods of the current oscillation became more marked in the order $\mathrm{Cl}^{-}, \mathrm{Br}^{-}$and $\mathrm{I}^{-}$.

\subsubsection{Effects on lower current and inhibited}

time Figure 5 shows effects of halide ions on the lower current of the oscillations, schematically shown in Fig. $3 c-d,(\Delta \square)$ or the constant current densities of current-time curves $(\triangle \square \bigcirc)$. As the concentrations of halide ions became higher, the lower current densities gradually shifted to higher one. At last, the current oscillation disappeared and the current showed a constant value. The concentrations at which the current oscillation disappeared were $50 \mathrm{mM}$ for $\mathrm{Cl}^{-}, 5 \mathrm{mM}$ for $\mathrm{Br}^{-}$and $0.1 \mathrm{mM}$ for $\mathrm{I}^{-}$. This result also shows that the inhibitory behavior of DOOA is weakened by halide ions in the order $\mathrm{Cl}^{-}, \mathrm{Br}^{-}$ and $\mathrm{I}^{-}$. The specific adsorption of $\mathrm{Cd}^{2}+$ induced by halide ions may become strong in this order.

Figure 6 shows effects of $\mathrm{Cl}^{-}$and $\mathrm{Br}^{-}$on the inhibited time (Fig. $3 \mathrm{I}$ ). The effect of $\mathrm{I}^{-}$on the inhibited time could not be measured because the current oscillation disappeared at very low concentration of $\mathrm{I}^{-}$. The inhibited time became shorter with increase in concentration of $\mathrm{Cl}^{-}$and $\mathrm{Br}^{-}$. The surface concentration of $\mathrm{Cd}^{2}+$ decreased by reduction and deposition during activated time (Fig. 3A) is restored by the diffusion of $\mathrm{Cd}^{2}+$ from the bulk of solution during inhibited time ${ }^{11,12}$, therefor the surface concentration of $\mathrm{Cd}^{2+}$ at the end of the inhibited time (Fig. $3 \mathrm{~d}$ ) become lower with shortening the inhibited time. As the surface concentration of $\mathrm{Cd}^{2+}$ at the end of inhibited time is that at which the strong inhibitory behavior of DOOA for the reduction of $\mathrm{Cd}^{2}+$ is disappeared12), it is indicated that the inhibitory behavior of DOOA is weakened at the lower surface concentration of $\mathrm{Cd}^{2}+$ in the presence of halide ions. The inhibitory behavior of DOOA may be weakened as follows. The strong electrostatic repulsive force between adsorbed DOOA cations, which are formed by addition of a proton 3$)$, and $\mathrm{Cd}^{2}+$ may be weakened by halide ions. Halide ions may form paths in positively charged adsorption layer through which $\mathrm{Cd}^{2+}$ penetrate to the surface of cadmium cathode.
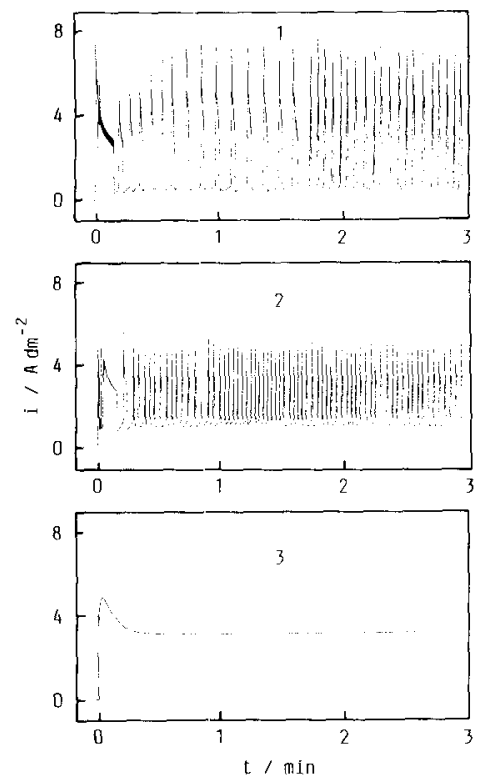

Fig. 4 Effects of halide ions on the current oscillation during electrocrystallization of cadmium in the presence of DOOA at $-0.95 \mathrm{~V}$.

1) $0.5 \mathrm{M} \mathrm{H}_{2} \mathrm{SO}_{4}+0.4 \mathrm{M} \mathrm{CaSO}+5 \mathrm{mM} \mathrm{DOOA}+1 \mathrm{mM}$ $\mathrm{KCl}$, 2) $0.5 \mathrm{M} \mathrm{H}_{2} \mathrm{SO}_{4}+0.4 \mathrm{M} \mathrm{CdSO}_{4}+5 \mathrm{mM} \mathrm{DOOA}+$ $1 \mathrm{mM} \mathrm{KBr}$, 3) $0.5 \mathrm{M} \mathrm{H}_{2} \mathrm{SO}_{4}+0.4 \mathrm{M} \mathrm{CdSO}+5 \mathrm{mM}$ $\mathrm{DOOA}+1 \mathrm{mMKI}$.

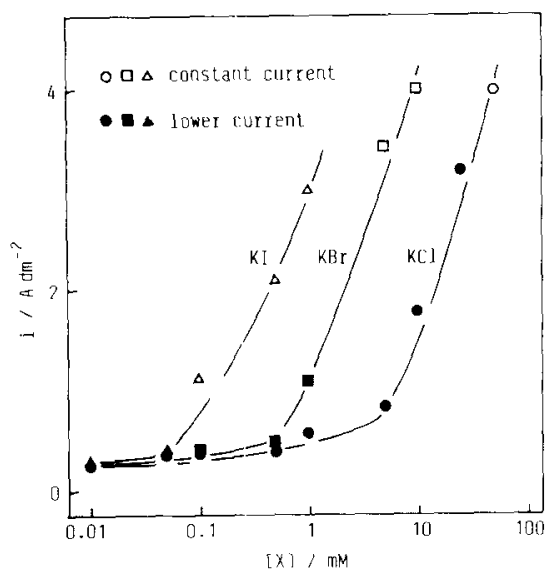

Fig. 5 Plots of lower current densities of the oscillations and constant current densities of the currenttime curves vs. logarithm of concentration of halide ions at $-0.95 \mathrm{~V}$.

$0.5 \mathrm{M} \mathrm{H}_{2} \mathrm{SO}_{4}+0.4 \mathrm{M} \mathrm{CdSO}_{4}+5 \mathrm{mM} \mathrm{DOOA}+[\mathrm{X}]$, $\mathrm{X}=\mathrm{KCl}, \mathrm{KBr}$, $\mathrm{KI}$. 


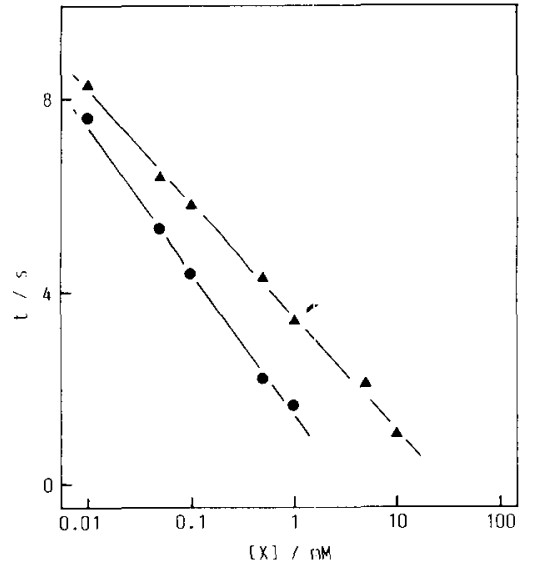

Fig. 6 Plots of inhibited time of the current oscillations vs. logarithm of concentration of halide ions at $-0.95 \mathrm{~V}$.

$0.5 \mathrm{M} \mathrm{H}_{2} \mathrm{SO}_{4}+0.4 \mathrm{M} \mathrm{CdSO}_{4}+5 \mathrm{mM} \mathrm{DOOA}+[\mathrm{X}]$, $\mathrm{X}=\mathrm{KCl}, \mathrm{KBr}$.

\subsubsection{Effects on upper current and activat-} ed time Figure 7 shows effects of $\mathrm{Cl}^{-}$and $\mathrm{Br}^{-}$ on upper current of the oscillations, schematically shown in Fig. 3 a. The upper current density shifted to lower one with increase in concentration of halide ions. The surface concentration of $\mathrm{Cd}^{2+}$ at the beginning of activated time (Fig. 3 a) is equal to that at the end of inhibited time (Fig. 3 d), therefor the upper current density is determined by the surface concentration of $\mathrm{Cd}^{2+}$ at the end of inhibited time11,12). Thus, the upper current density is shifted to lower one as the surface concentration of $\mathrm{Cd}^{2+}$ at the end of inhibited time becomes lower with shortening inhibited time. Furthermore, the activated time becomes shorter with increase in concentration of halide ions (Fig. 2). The activated time becomes shorter with decrease in the surface concentration of $\mathrm{Cd}^{2}+$ at the beginning of activated time, i.e., the surface concentration at the end of inhibited time, because the surface concentration of $\mathrm{Cd}^{2}+$ decreases more quickly to the critical value ${ }^{12)}$, at which the strong inhibitory behavior of DOOA appears 11,12 ).

As described in 3.2.1 and 3.2.2, the amplitude and the period of the oscillation became smaller and shorter as a result that inhibitory behavior of DOOA was weakened by halide ions.

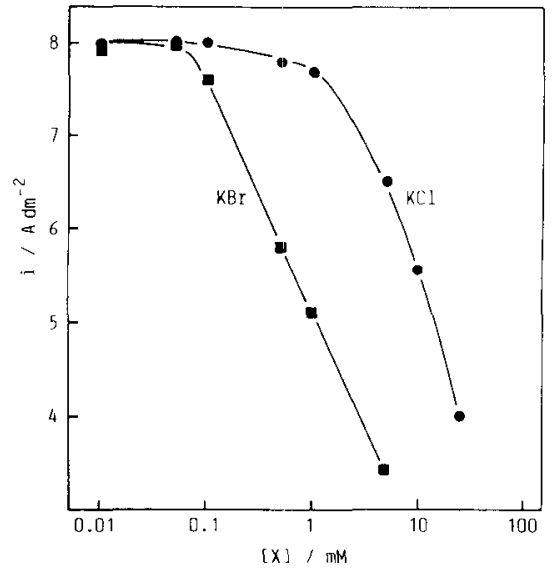

Fig. 7 Plots of upper current densities vs. logarithm of concentrations of halide ions at -0.95 V.

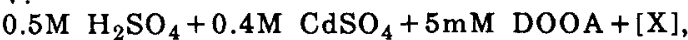
$\mathrm{X}=\mathrm{KCl}, \mathrm{KBr}$.

\subsection{Effects of halide ions on surface mor-} phology

Figure 8 shows scanning electron micrographs (SEM) of electrodeposited cadmium which was obtained at $-0.95 \mathrm{~V}$ in the presence of DOOA and $\mathrm{Br}^{-}$. The small cadmium crystals with irregular edges were observed on the whole surface of electrodeposited cadmium which was obtained in the presence of DOOA alone (Fig. 8 A). In the presence of DOOA and $\mathrm{Br}^{-}$, the aggregates of small plate - like cadmium crystals (sides $1-3 \mu \mathrm{m}$ ) were observed (Fig. $8 \mathrm{~B}, \mathrm{C}$ ). Surface roughness of the electrodeposited cadmium became larger and thickness of the small platelike crystals became thicker with increase in concentration of $\mathrm{Br}^{-}$. This result indicated that the inhibitory behavior of DOOA for the amplification of surface roughness and the growth of cadmium crystal was weakened by $\mathrm{Br}^{-}$. Similar results were obtained by addition of $\mathrm{Cl}^{-}$or $\mathrm{I}^{-}$.

Figure 9 shows SEM of electrodeposited cadmium which was obtained in the presence of 5 $\mathrm{mM}$ of DOOA and $1 \mathrm{mM}$ of halide ions. The small crystals with irregular edges were observed on the surface of electrodeposited cadmium which was obtained in the presence of DOOA and $\mathrm{Cl}^{-}$ (Fig. $9 \mathrm{~A}$ ). The size and form of these small crystals were similar to that in the presence of 
A

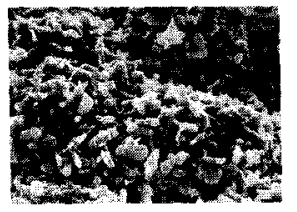

$c$

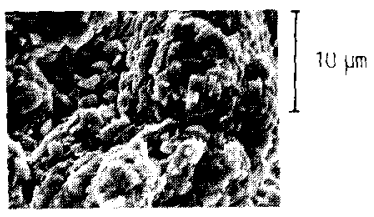

Fig. 8 Effect of $\mathrm{Br}^{-}$on the surface morphology of electrodeposited cadmium obtained in the presence of DOOA at $-0.95 \mathrm{~V}$.

A) $0.5 \mathrm{M} \mathrm{H}_{2} \mathrm{SO}_{4}+0.4 \mathrm{M} \mathrm{CdSO}_{4}+5 \mathrm{mM} \mathrm{DOOA}$,

B) A) $+0.5 \mathrm{mM} \mathrm{KBr}$, C) A) $+5 \mathrm{mM} \mathrm{KBr}$.

DOOA alone (Fig. $8 \mathrm{~A}$ ). The aggregates of platelike crystals with round edges were observed in the presence of DOOA and $\mathrm{Br}^{-}$(Fig. $9 \mathrm{~B}$ ). The aggregates of plate-like crystals with clear edges were observed in the presence of DOOA and $\mathrm{I}^{-}$(Fig. $9 \mathrm{C}$ ). The regularity of the small crystals increased in the order $\mathrm{Cl}^{-}, \mathrm{Br}^{-}$and $\mathrm{I}^{-}$. Small cadmium crystals with irregular form were deposited in the cases that DOOA cations form a very compact adsorption layer (at negative potentials) and aggregates of plate-like crystals with clear edges were deposited in the case that DOOA cations can not form a compact adsorption layer (at positive potentials) ${ }^{12}$ ). The transformation of small crystals from irregular to regular form shows that a compact adsorption layer of DOOA is made to be loose by halide ions in the order $\mathrm{Cl}^{-}, \mathrm{Br}^{-}$and $\mathrm{I}^{-}$. The growth of cadmium crystal may be isotropically and strongly inhibited by a very compact adsorption layer of DOOA when the $\mathrm{Cl}^{-}$is added into the solution. On the other hand, the anisotropy of crystal growth 13 ) due to the characteristics of crystal planes of cadmium (density of cadmium atom, concentrations of DOOA and $\mathrm{Cd}^{2}+$ on each crystal planes) may appear when $\mathrm{Br}^{-}$or $\mathrm{I}^{-}$is added. Cadmium crystals show the form which was determined by the characteristics of each crystal planes.

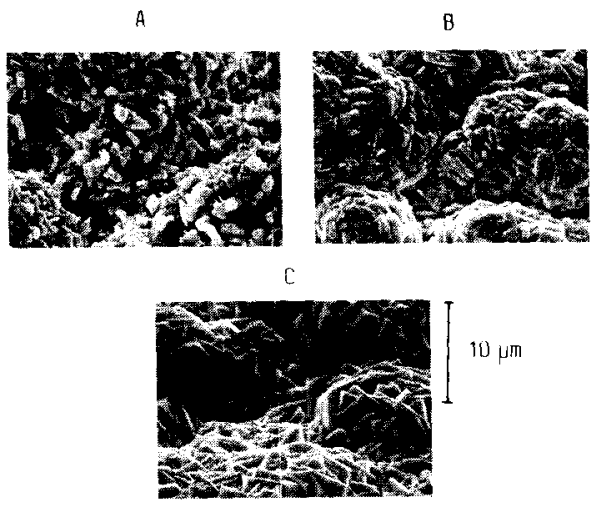

Fig. 9 Effect of halide ions on the surface morphology of electrodeposited cadmium obtained in the presence of DOOA at $-0.95 \mathrm{~V}$.

A) $0.5 \mathrm{M} \mathrm{H}_{2} \mathrm{SO}_{4}+0.4 \mathrm{M} \mathrm{CdSO}+5 \mathrm{mM} \mathrm{DOOA}+1 \mathrm{mM}$ $\mathrm{KCl}$, B) $0.5 \mathrm{M} \mathrm{H}_{2} \mathrm{SO}_{4}+0.4 \mathrm{M} \mathrm{CdSO}_{4}+5 \mathrm{mM} \mathrm{DOOA}+$ $1 \mathrm{mM} \mathrm{KBr}$, C) $0.5 \mathrm{M} \mathrm{H}_{2} \mathrm{SO}_{4}+0.4 \mathrm{M} \mathrm{CdSO}_{4}+5 \mathrm{mM}$ DOOA + I mM KI

\section{CONCLUSIONS}

The conclusions obtained in this work can be summarized as follows.

1) The inhibitory behavior of DOOA for the reduction of $\mathrm{Cd}^{2}+$ in acidic cadmium sulfate solutions is weakened by addition of halide ions in the order that specific adsorption of halide ions become strong $\left(\mathrm{Cl}^{-}<\mathrm{Br}^{-}<\mathrm{I}^{-}\right)$.

2) The amplitudes and periods of current oscillation during electrocrystallization of cadmium in the presence of DOOA become small and short with increase in concentrations of halide ions, and the current oscillation is finally disappeared.

3) The regularity of the morphology of electrodeposited cadmiurn crystals increased by addition of halide ions in the order $\mathrm{Cl}^{-}, \mathrm{Br}^{-}$ and $\mathrm{I}^{-}$. The strong inhibitory behavior of DOOA for the crystal growth of cadmium was weakened by halide ions.

\section{REFERENCES}

1) N. Kaneko, H. Nezu and N. Shinohara, Denki Kagaku, 50,959 (1982).

2) N. Kaneko, N. Shinohara and H. Nezu, Electrochim. Acta, 38, 1351 (1993).

3) N. Kaneko, N. Shinohara, A. Iizawa and $H$. Nezu, Denki Kagaku, 60, 434 (1992).

4) M. A. V. Devanathan and M. J. Fernando, 
Trans. Faraday Soc., 58, 368 (1962).

5) J. B. Hayter and R. J. Hunter, J. Electroanal. Chem., 37, 71 (1972).

6) J. B. Hayter and R. J. Hnter, J. Electroanal. Chem., 37, 81 (1972).

7) A. Hamelin, Compte Rend., C262, 520 (1966).

8) G. W. O'Dom and R. W. Murray, Anal. Chem., 39, 51 (1967).

9) F. C. Anson and D. J. Barclay, Anal. Chem., 40, 1791 (1968).
10) N. Kaneko, A. Iizawa, Y. Nakamura and $H$. Nezu, Denki Kagaku, 62, 78 (1994).

11) N. Shinohara, N. Kaneko and H. Nezu, Bunseki Kagaku, 40, 647 (1991).

12) N. Shinohara, N. Kaneko and H. Nezu, Denki Kagaku, 62, 39 (1994).

13) T. Kuroda, Kotai Buturi, 20, 710 (1985). 